\title{
CLINICAL TREATMENT APPROACH OF A CHILD WITH MOLAR INCISOR HYPOMINERALIZATION (MIH) COMBINED WITH MALOCCLUSION
}

\author{
Rossitza Kabaktchieva ${ }^{1}$, Vladimir Bogdanov ${ }^{2}$ \\ 1) Department of Pediatric Dental Medicine, Faculty of Dental Medicine, Sofia \\ 2) Department of Orthodontics, Faculty of Dental Medicine, Sofia, Bulgaria
}

\begin{abstract}
Introduction. Molar incisor hypomineralization (MIH) was defined as "hypomineralisation of systemic origin of permanent first molars, frequently associated with affected incisors". MIH includes the presence of demarcated opacity, post eruptive enamel breakdown, atypical restoration. The approach to management suggested: risk identification, early diagnosis, remineralization for prevention of caries and post eruption breakdown, restorations. The clinicians very seldom notice that children with MIH usually have both- hypomineralisation and malocclusions, and they do not discuss combine treatment
\end{abstract} plan.

Aim. To present our interdisciplinary approach to a patient with $\mathrm{MIH}$, combined with malocclusion.

Material and methods. We are presenting 9 year old child with contusio and fractura coronae dentis noncomplicata, distal occlusion, overjet,overbite and retrusion. Two consecutive stages were defined:

First stage:

- Professional oral hygiene and local remineralisation therapy

- Vital pulp therapy of tooth 21

- Space gaining for restoration of the lost height of the molars by the means of posterior bite-plane removable appliance

- Restoration of the molars with metal inlays

- Lingual tipping of the lower incisors

Second stage:

- Class II correction

- Growth control

Results.

First phase:

=The tooth 21 was restored with aesthetic composite material;

- Occlusion was raised with occlusal restorations ( inleys) and orthodontic appliance.

\section{Second phase:}

Medialisation of mandible and holding maxillary growth with functional appliance and occipital EOA until class one occlusal relations.
Conclusion. Children with MIH should be examined and treated complex in collaboration with orthodontist and if necessary by other specialists too.

Key words. Molar incisor hypomineralization (MIH)

\section{INTRODUCTION.}

Molar Incisor Hypomineralisation is defined as hypomineralisation of systemic origin emerging during the development of the first permanent molars and first permanent incisors $(18,21)$. MIH is one of the forms of structural abnormalities during tooth development, also referred as tooth dysplasia (11). The most common aethiological factors include neonatal problems, sicknesses during early childhood, or medically compromised children $(2,3,8,11,12,15,20,24)$. Moreover genetic predisposition is also possible $(1,15) \mathrm{MIH}$ is presented with clearly defined white non-transparent spots on the affected teeth, followed by posteruptive decay. The main reason for this is soft and porous enamel which leads to atypical cavities (followed by atypical restorations) or to thorough destruction of the crown (11, 21). Jalevik B. - 2010 (9) in his systematic review reported many studies on diagnostic criteria, concerning MIH (Weerheijm et al., 2003)(21). Patients and parental common complaints included affected esthetics, rapid wear and loss of enamel, caries, sensitivity to cold air, hot water, food, brushing and as a final result destruction and loss of the affected teeth $(10,13,24)$. Poor oral hygiene leading to plaque accumulation, contributes fast progress of decay $(13,17)$.

Since 2000 eleven review articles evaluated and described the therapeutic options and management of the hypomineralisations of the enamel $(4,5,6,7,16,17,18$, $19,22,23,24)$. Treatment approach consists of early diagnosis, caries risk management, remineralisation therapy for prevention of the decay and caries, restorations. Molar restorations could be composite restorations, metal inlays and crowns, depending on the occasion. Esthetic fillings or veneers are appropriate solutions for the anterior teeth. William et al. recommend a 6 stage approach to treating MIH (22). 
General dental practitioners tend to neglect the fact, that the affected molars are to be lost and consequences for the dentition from orthodontic point of view (23), and often do not consider interdisciplinary treatment. Hypomineralisation defects attract professional attention, being difficult to treat $(11,14,18,22)$.

Aim. To present our interdisciplinary approach to a patient with $\mathrm{MIH}$, combined with malocclusion.

\section{MATERIAL AND METHODS:}

\section{Case Report.}

Nine year old patient (N.P.) was examined at the Department of Pediatric Dental Medicine and diagnosed with Contusio et Fractura coronae dentis non complicata, affecing tooth 21 (fig. 1a). During examination the patient was diagnosed also with molar incisor hypomineralisation - defined white non-transparent spots on the vestibular surfaces of the maxillary and mandibular incisors (fig. 1a, b), and first permanent molars were restored with big amalgam fillings (fig. 2). Malocclusion presented was: skeletal and dental Class II, high angle $\left(\mathrm{M} / \mathrm{SN}=46^{\circ}\right)$, overjet $4 \mathrm{~mm}$., overbite, retroclined maxillary incisors (I/ $\left.\mathrm{SN}=96^{\circ}\right)$, proclined mandibular incisors $\left(\mathrm{i} / \mathrm{M}=98^{\circ}\right)$, gummy smile (fig. 3a, b, c). Patient presented poor oral hygiene, and a hyperplastic gingivitis (fig. 1a, b )

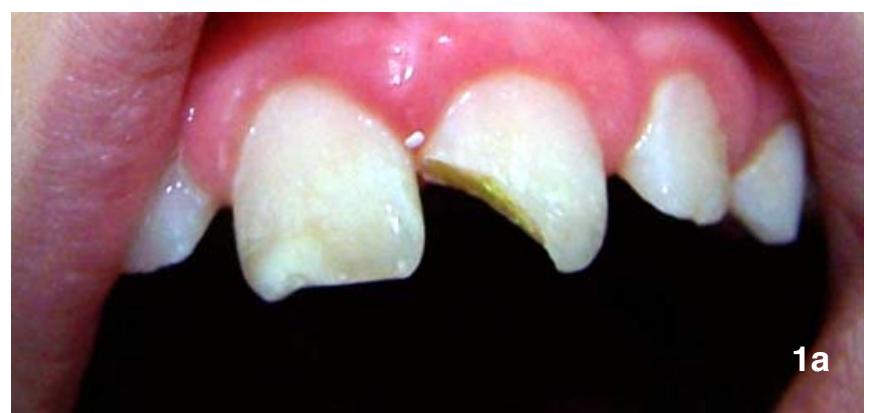

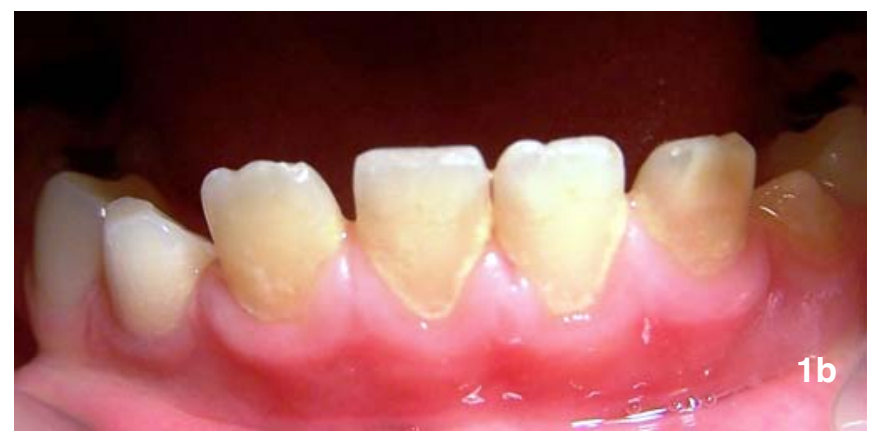

Fig. 1. Incisors of N.P., 9 year old presenting contusio et fractura coronae dentis non complicata, affecting tooth 21 . Defined white non-transparent spots on the vestibular surfaces of the maxillary and mandibular incisors are clearly visible. Poor oral hygiene with accompanying hypertrophy gingivitis.

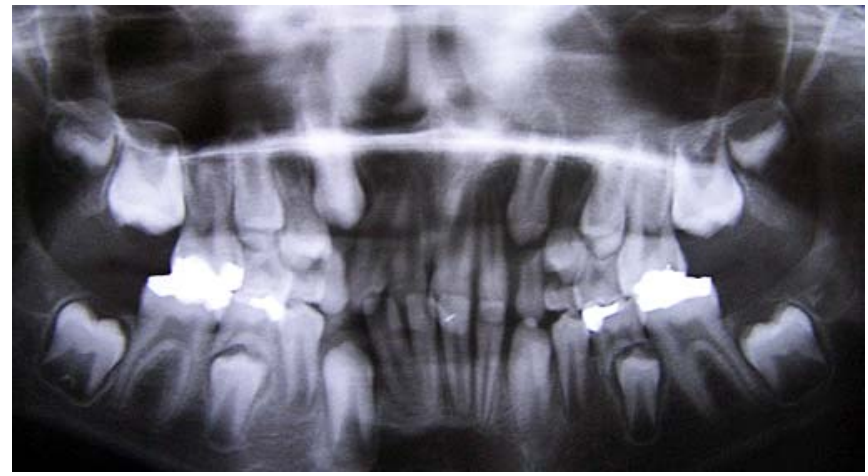

Fig. 2. Panoramic radiograph of N.P., 9 year old. Both upper and lower first permanent molars are restored with big amalgam fillings.
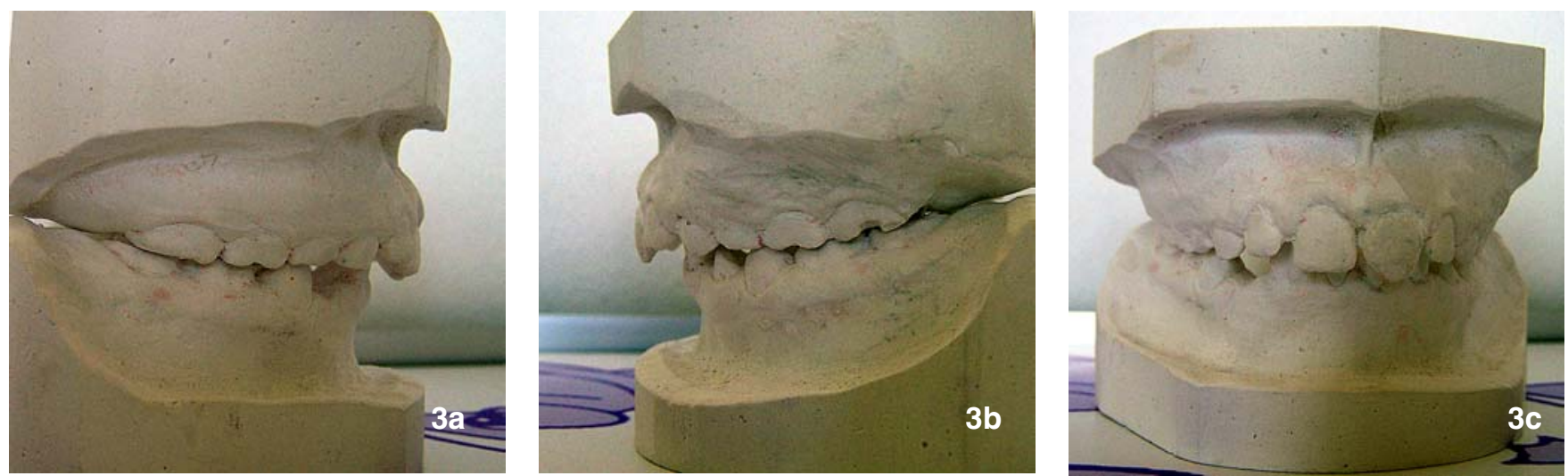

Fig. 3. Plaster diagnostic models of N.P., 9 year old. (shortened crowns of the molars due to decay, deep and distal occlusion) 
Treatment planning was performed by a specialist of pediatric dentistry and orthodontist. Two consecutive stages were defined:

\section{First stage:}

Professional oral hygiene and local remineralisation therapy.

Vital pulp therapy of tooth 21

Space gaining for restoration of the lost height of the molars by the means of posterior bite-plane removable appliance. Molars were not covered by the acrylic.

Restoration of the molars with metal inlays

Lingual tipping of the lower incisors

\section{Second stage:}

Class II correction

Growth control

\section{RESULTS:}

Treatment was started with professional oral hygiene and instructions for excellent oral hygiene. The patient was instructed to avoid biting on the traumatized tooth, prescribing fluoride mouthwash and use of Tooth Mousse as prescribed. Special attention was given to the traumatized tooth as after the trauma vitality was affected (70 MA). The status required avoiding from function, and monitoring of the pulp vitality. Adjacent maxillary and mandibular teeth were within normal range, concerning pulp vitality. Dycal covering of the exposed dentin and GIC filling were made (fig. $4 \mathrm{a}, \mathrm{b}$ ).

Fig. 5a, b. Study casts with bite registration for construction of the lower lingual plate and inlays.
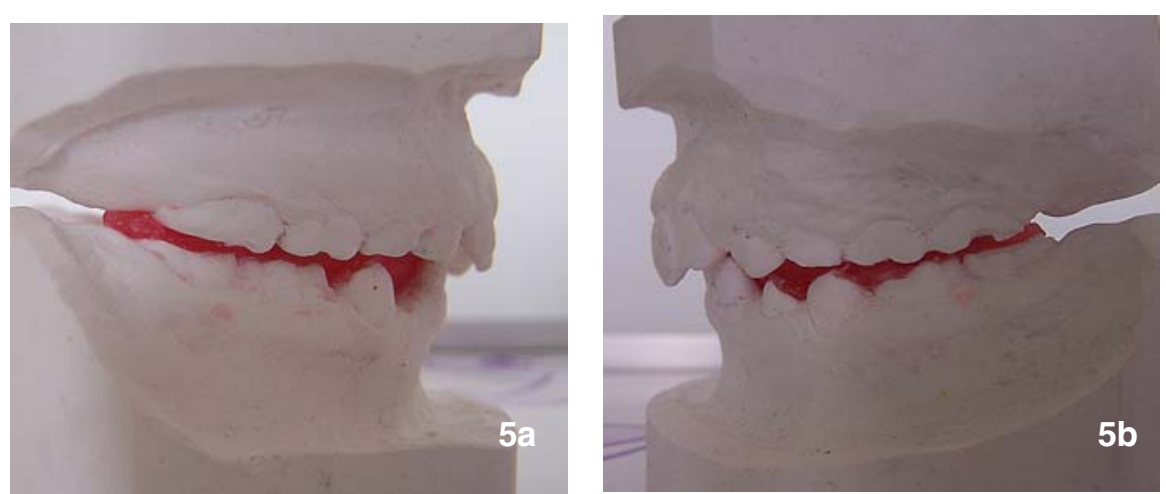
After bite registration, amalgam fillings were removed and the teeth were prepared for metal inlays. Molars were vital and the pulps were covered with liners. Inlays were made in the laboratory, according to the bite registration taken (fig. 6 a, b, c). Lingual plate with posterior bite plane and vestibular bow was made (fig. 7 a, b, c, d). Bite plane thickness is within the physiologic rest position of the mandible and leaves occlusal surfaces of the first permanent molars uncovered. The purpose is to let enough space for restorations. Labial bow with $\mathrm{U}$ bends is used to retract lower incisors. Recurved clasps on lower first molars provide anchorage and retention. Inlay adjustments and fixing is in the same day, the appliance is fitted (in this case $-15^{\text {th }}$ day) .The patient was advised to eat with the appliance in the mouth. Through gradual trimming of the bite plane first molars will be intruded enough, to level the occlusal plane.
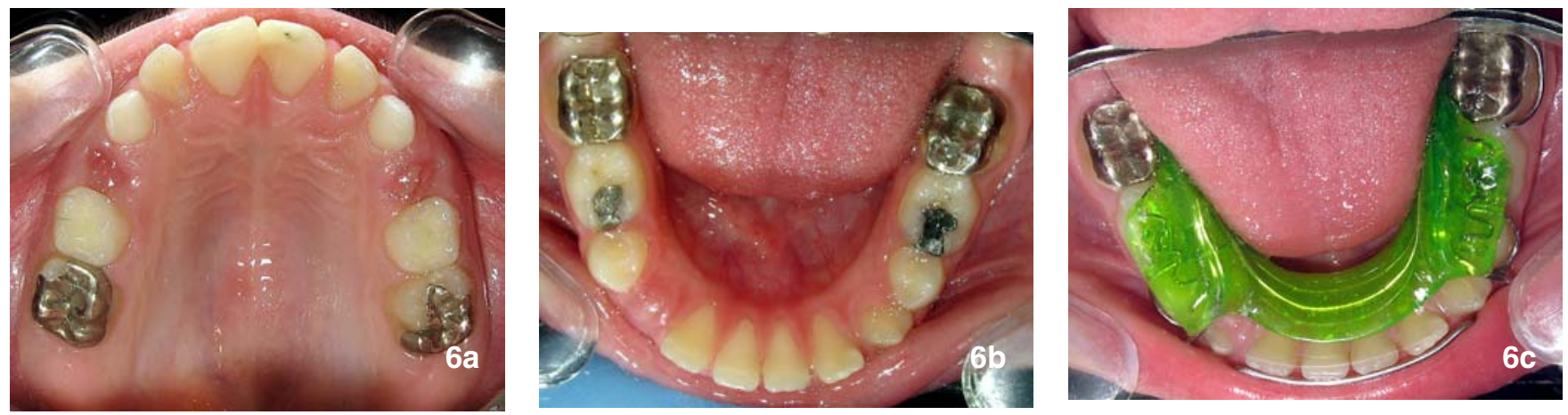

Fig. 6 a, b, c. Occlusal anatomy of the first molars, restored with inlays at the desired height
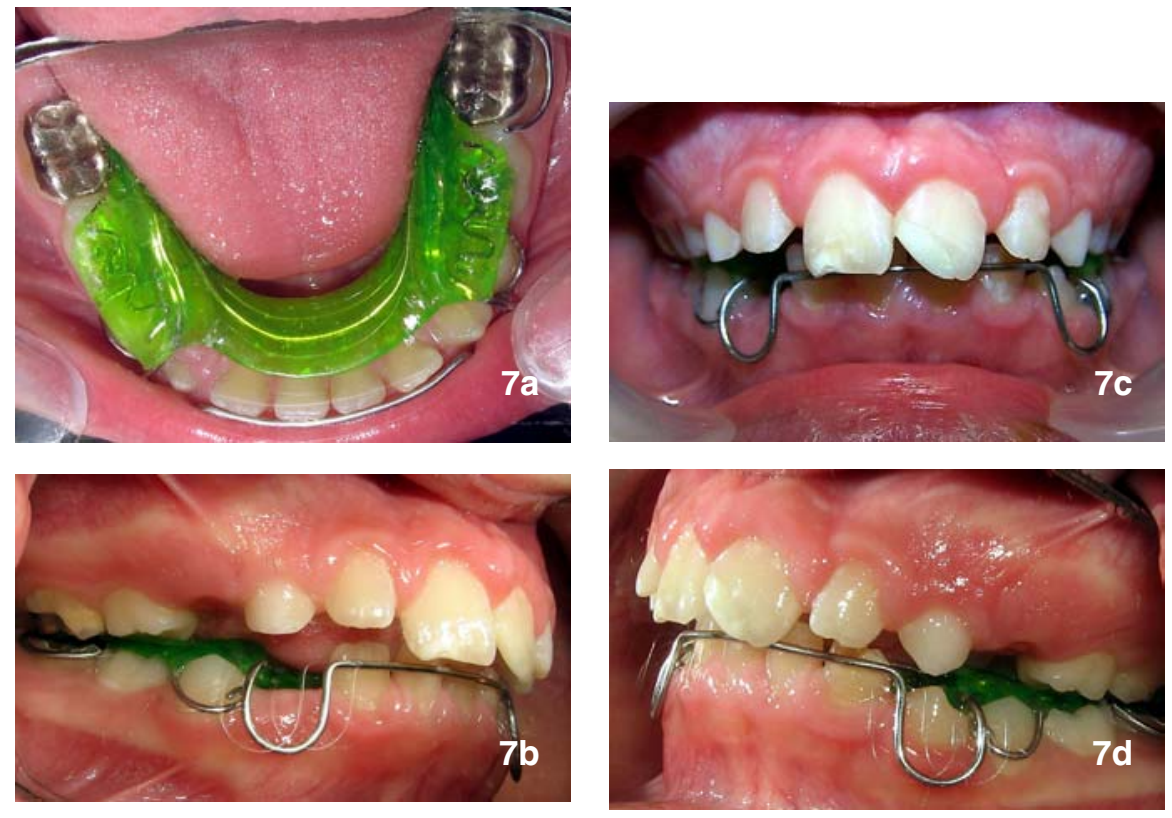

Fig. 7a, b, c, d. Removable lingual plate with bite plane (opening 1,5-2.0 $\mathrm{mm}$ within the physiologic rest position of the mandible) leaves the occlusal surfaces of the first permanent molars uncovered, labial bow with $U$ bends (a). Fixed inlays and fitted appliance (b, c, d)

Vitality of tooth 21 was closely monitored for 2,5 months. The tooth was vital ( $3 \mathrm{MA})$ and restoration was not risky. The restoration was performed with adhesive composite and post (fig. $8 \mathrm{a}, \mathrm{b}$ ) 

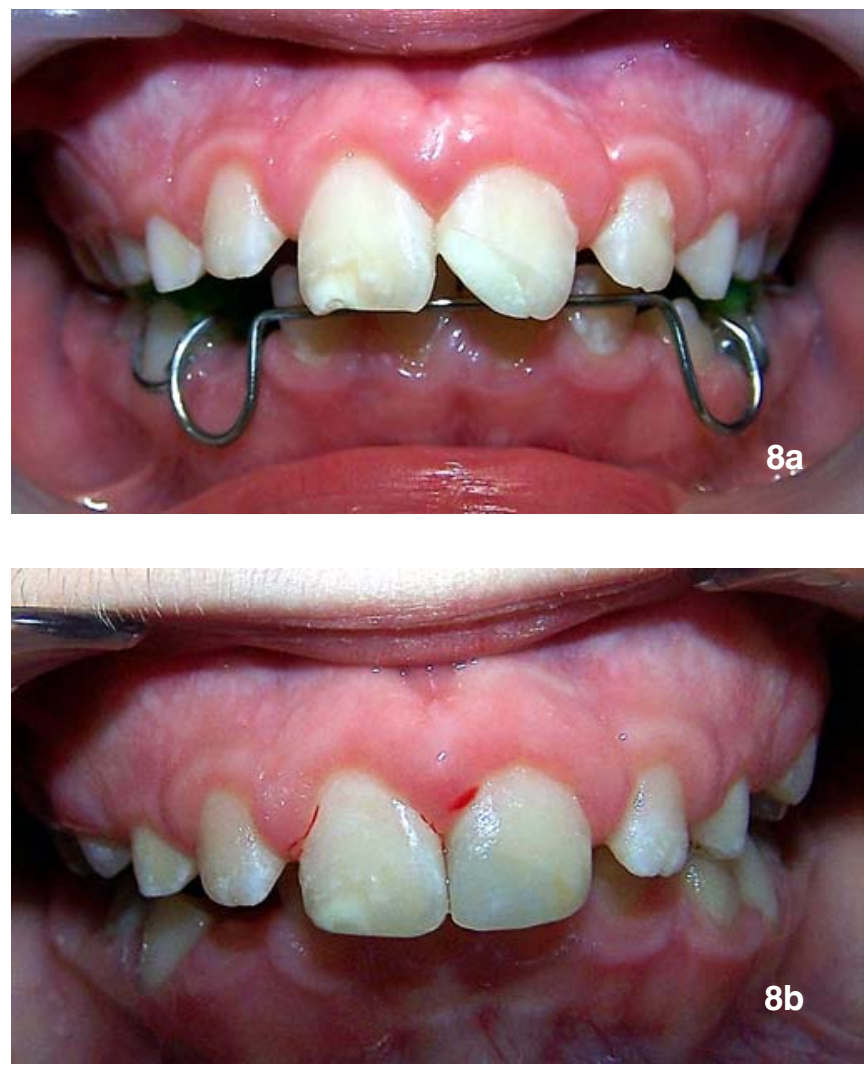

Fig. 8 a, b. (a) Fractura coronae dentis 21 sine collisione pulpae - after treatment. (b) Restoration of the fractured 21 tooth ( 80 days after the trauma), and incisal edge of 11 tooth.

It took four months to retract lower incisors by means of grinding the bite plane and feeding with the appliance, the molars were intruded. As the patient presents high angle growth pattern and skeletal Class II, further rising of the lower facial height is highly undesirable.

The second stage of the treatment plan included stimulation of forward growth of the mandible and suppressing vertical and forward growth of the maxilla. For achieving that aim activator (fig. 9 a, b, c) and occipital pull headgear were used. The outer bow used was with short arms and line of force through CRes. of the maxilla/ (fig. $10 \mathrm{a}, \mathrm{b})$. Improvement has been achieved and patient still wears appliances. For final leveling and alignment bonding of brackets is recommended.
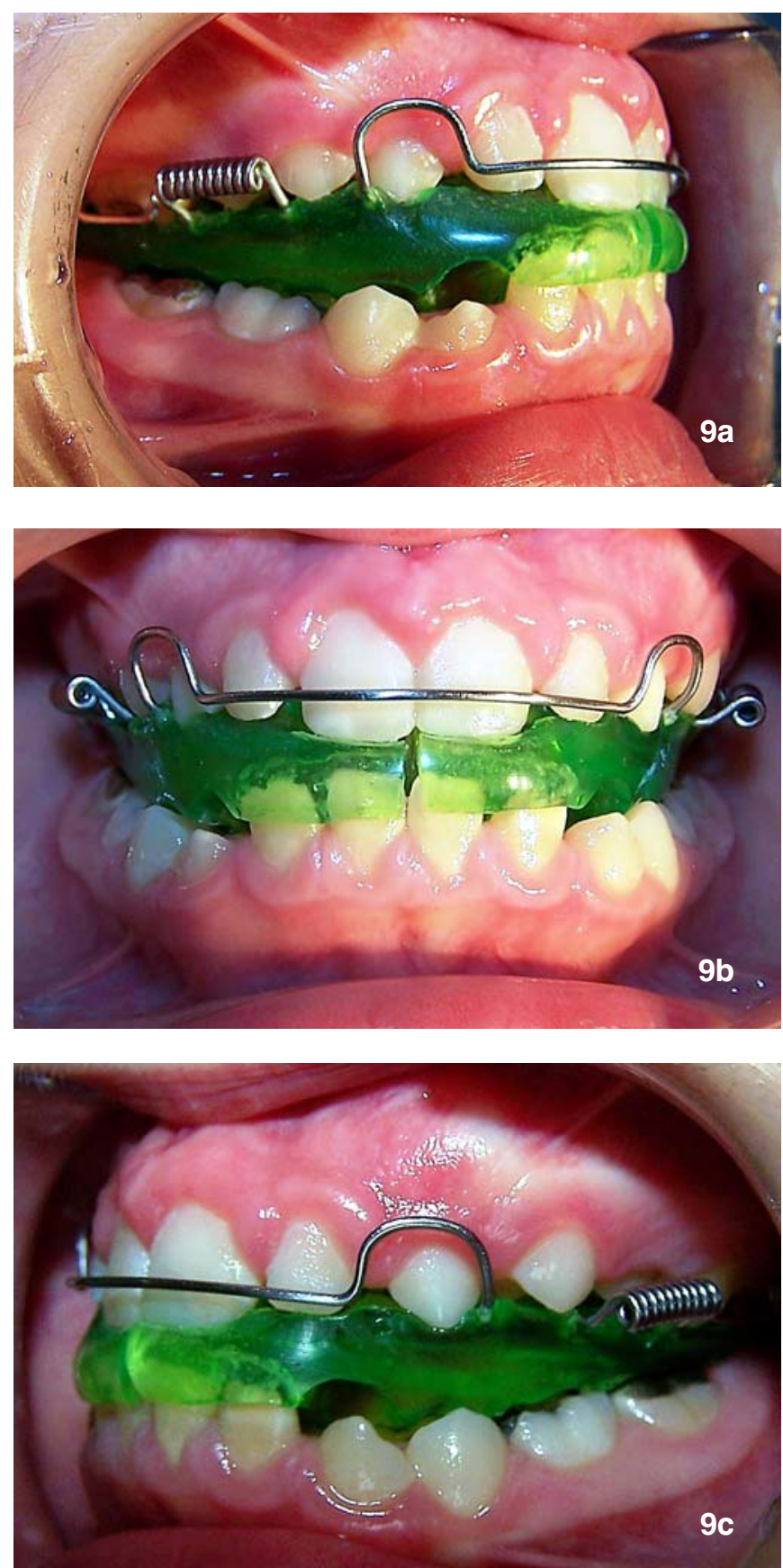

Fig. 9 a, b, c. Activator with interocclusal distance of approximately $5 \mathrm{~mm}$. 

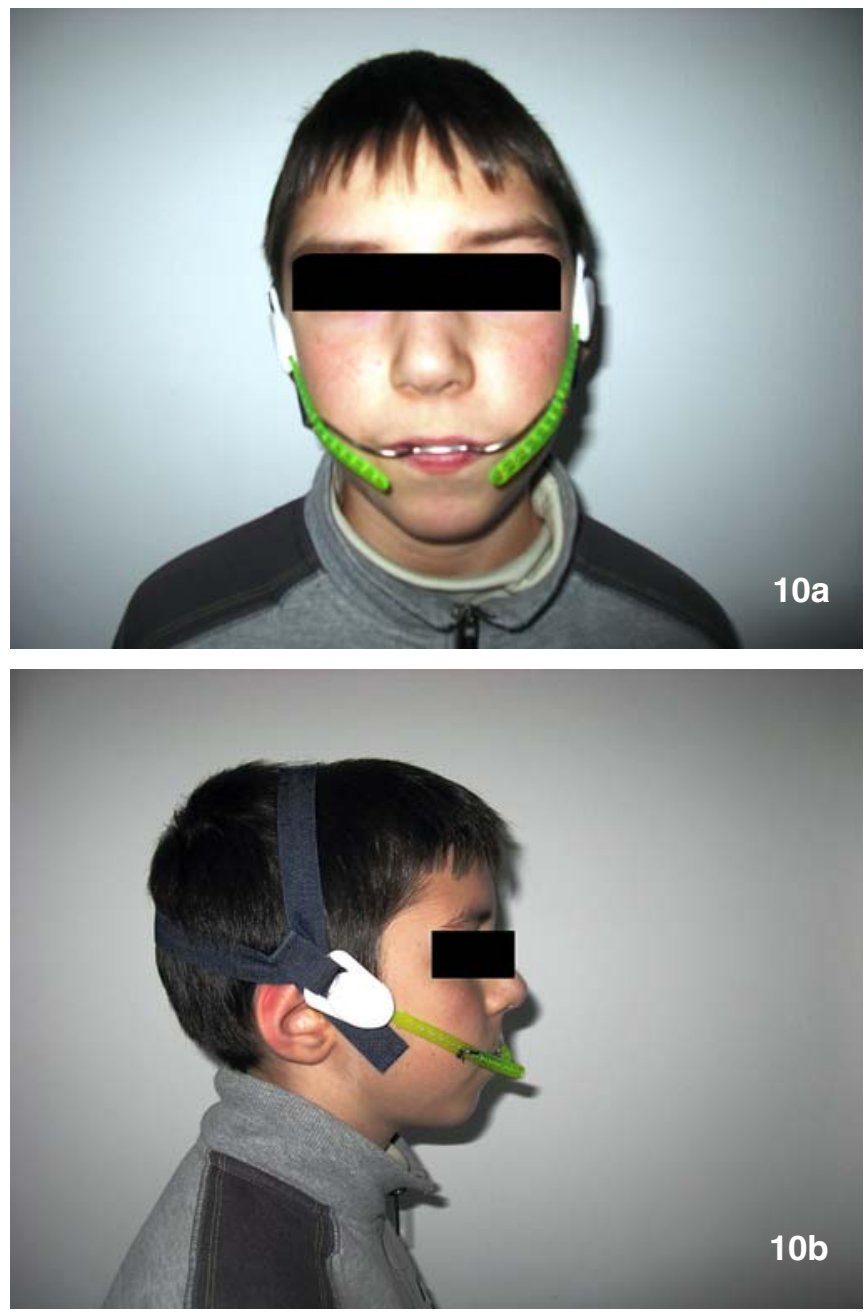

Fig. 10 a, b. High pull headgear. Short arms outer bow is with and line of force through CRes. of the maxilla. Growth modification is expected.

\section{DISCUSSION}

Clinical case of a child with trauma of the upper front teeth, fracture of the upper central incisor, molar incisor hypomineralisation affecting molar and incisor enamel and class II malocclusion has been presented. Medical history reveals that after the age of two years the patient suffered repeatedly rhinitis, otitis, bronchitis and tonsillitis. Dental history reveals that first molars were yellowish and spotted immediately after eruption and started to decay quickly. Our long clinical experience concerning diagnostics and treatment of dental dysplasia (1) depicted that the patient presents MIH (acquired dental dysplasia) and medical and dental history support this. In order to prevent further destruction amalgam fillings were made on his first permanent molars. No other preventive procedures were performed. The patient was redirected to the Faculty of Dental Medicine after the fracture of the incisor. A case, presenting fracture, $\mathrm{MIH}$ and malocclusion is a serious clinical challenge. Complicated case like this supposes an interdisciplinary treatment including paedodontist and orthodontist. Two stage treatment plan was composed. The aim of the treatment performed was biological treatment of the tooth 21, esthetical frontal restorations and anatomical restorations on the molars with metal inlays. Regaining the lost height was performed by means of removable lingual plate with bite plane. At the same time orthodontic treatment was performed. Lingual tipping of the lower incisors, Class II correction, growth control are the main aims of the orthodontic treatment. Tight control of the oral hygiene and orthodontic correction are the key to achieve gingival health.

\section{CONCLUSION:}

The case shows that every incident that has brought a child to the dental surgery (in this particular case a dental trauma), requires thorough examination. Patients, presented with MIH must be discussed by a team of specialists. The key for successful treatment of patients with MIH is early diagnosis, team work and intensive follow-up.

\section{REFERENCES}

1. Alaluusua S. Aetiology of MolarIncisor Hypomineralisation. A systematic review. Eur Archs Paediatr Dent. 2010 Apr;11(2):53-58. [PubMed]

2. Beentjes VE, Weerheijm KL, Groen HJ. Factors involved in the aetiology of molar-incisor hypomineralisation (MIH). Eur J Paediatr Dent. 2002 Mar;3(1):9-13. [PubMed]

3. Crombie F, Manton D, Kilpatrick N. Aetiology of molar-incisor hypomineralisation: a critical review. Int J Paediatr Dent. 2009 Mar;19(2):73-83. [PubMed]
[CrossRef]

4. Croll TP. Restorative options for malformed permanent molars in children. Compend Contin Educ Dent. 2000 Aug;21(8):676-678, 680, 682. [PubMed]

5. Daly D, Waldron JM. Molar incisor hypomineralisation: clinical management of the young patient. J Ir Dent Assoc. 2009 Apr-May;55(2):83-86. [PubMed]

6. Fayle SA. Molar incisor hypomineralisation: restorative management. Eur J Paediatr Dent. 2003 Sep;4(3): 121-126. [PubMed]
7. Fitzpatrick L, O'Connell A. First permanent molars with molar incisor hypomineralisation. J Ir Dent Assoc. 2007 Spring;53(1):32-37. [PubMed]

8. Hong L, Levy SM, Warren JJ, Dawson DV, Bergus GR, Wefel JS. Association of amoxicillin use during early childhood with developmental tooth enamel defects. Arch Pediatr Adolesc Med. 2005 Oct;159(10):943-948. [PubMed]

9. Jalevik B. Prevalence and Diagnosis of Molar-Incisor-Hypomineralisation (MIH). A systematic review. Eur Archs 
Paediatr Dent. 2010 Apr;11(2):59-64. [PubMed]

10. Jalevik, B. Klingberg GA. Dental treatment, dental fear and behaviour management problems in children with severe enamel hypomineralisation of their permanent first molars. Int J Paediatr Dent. 2002 Jan;12(1): 24-32. [PubMed] [CrossRef]

11. Kabaktchieva R. Study on Dental dysplasiae and alternatives for primary and secondary prevention, Ph.D. Thesis, 1989, Sofia, 148 and supplement (in Bulgarian)

12. Laisi S, Ess A, Sahlberg C, Arvio P, Lukinmaa PL, Alaluusua S. Amoxicillin may cause molar incisor hypomineralisation. J Dent Res. 2009 Feb;88(2):132-136. [PubMed] [CrossRef]

13. Leppaniemi A, Lukinmaa P-L, Alaluusua S. Nonfluoride Hypomineralisation in the permanent first molars and their impact on treatment need. Caries Res. 2001 Jan-Feb;35(1):36-40. [PubMed] [CrossRef]

14. Lygidakis NA, Chaliasou A, Siounas G. Evaluation of composite restorations in hypomineralised permanent molars: a fouryear clinical trial. Eur J Paediatr Dent. 2003 Sep;4(3):143-148. [PubMed]

15. Lygidakis NA, Dimou G, Marinou D. Molar-Incisor-Hypomineralisation (MIH). A retrospective clinical study in Greek children. II. Possible medical aetiological factors. Eur Arch Paediatr Dent. 2008 Dec; 9(4):207-17. [PubMed]

16. Lygidakis NA, Treatment modalities in children with teeth affected by molarincisor enamel hypomineralisation (MIH): a systematic review, Eur Archs Paediatr Dent. 2010 Apr;11(2):65-75. [PubMed]

17. Mahoney EK. The treatment of localised hypoplastic and hypomineralized defects in first permanent molars. $N Z$ Dent J. 2001 Sep;97(429):101-5. [PubMed]

18. Mathu-Muju K, Wright JT. Diagnosis and treatment of molar incisor hypomineralisation. Compend Contin Educ Dent. 2006 Nov;27(11):604-10. [PubMed]

19. Sapir S, Shapira J. Clinical solutions for developmental defects of enamel and dentin in children. Pediatr Dent. 2007 JulAug;29(4):330-6. [PubMed]
20. Whatling R, Fearne JM. Molar incisor hypomineralisation: a study of aetiological factors in a group of UK children. Int $J$ Paediatr Dent. 2008 May;18(3):155-162. [PubMed] [CrossRef]

21. Weerheijm KL, Duggal M, Mejare I, Papagiannoulis L, Koch G, Martens LC, et al. Judgement criteria for Molar-Incisor Hypomineralisation (MIH) in epidemiologic studies: a summary of the European meeting on MIH held in Athens, 2003. Eur $J$ Paediatr Dent. 2003 Sep;4(3):110-113. [PubMed]

22. William V, Messer LB, Burrow MF. Molar incisor hypomineralisation: review and recommendations for clinical management. Pediatr Dent. 2006 MayJun;28(3):224-32. [PubMed]

23. Williams JK, Gowans AJ. Hypomineralised first permanent molars and the orthodontist. Eur J Paediatr Dent 2003 Sep;4(3):129-132. [PubMed]

24. Willmott NS, Bryan RA, Duggal MS. Molar-incisor-hypomineralisation: a literature review. Eur Archs Paediatr Dent. 2008 Dec;9(4):172-9. [PubMed].

\section{Address for correspondence:}

Rossitza Kabaktchieva, Associate professor, $P h D, M D$

Department of Pediatric Dental Medicine, Faculty of Dental Medicine, Sofia 1, St. George Sofiiyski Str., 1000 Sofia, Bulgaria mob.: +359/888 099453

E-mail: r_kabaktchieva@mail.bg 